\title{
Autologous Stem Cell Transplantation in Multiple Myeloma in the Era of Novel Drug Induction: A Retrospective Single-Center Analysis
}

\author{
Gabriela B. Thoennissen ${ }^{a, b}$ Dennis Görlich ${ }^{c}$ Ulrike Bacher ${ }^{a, g}$ \\ Thomas Aufenberg $^{b}$ Anne-Christin Hüsken ${ }^{b}$ Anna Antonia Hansmeier ${ }^{b}$ \\ Georg Evers $^{\mathrm{b}}$ Jan-Henrik Mikesch ${ }^{\mathrm{b}}$ Fleur Fritz $^{\mathrm{d}}$ Carsten Bokemeyer $^{\mathrm{a}}$ \\ Carsten Müller-Tidow $^{b}$, e Matthias Stelljes ${ }^{b}$ Rolf M. Mesters $^{b}$ Utz Krug ${ }^{b, f}$ \\ Martin H. Kropff ${ }^{b}$ Nils H. Thoennissen ${ }^{a, b}$ Wolfgang E. Berdel ${ }^{b}$ \\ a Department of Oncology, Hematology, and Bone Marrow Transplantation with Section of Pneumology, Hubertus \\ Wald University Cancer Center, University Medical Center Hamburg-Eppendorf, Hamburg, ${ }^{b}$ Department of \\ Medicine, Hematology/Oncology/Pneumology, ${ }^{C}$ Institute of Biostatistics and Clinical Research, and ${ }^{\mathrm{d}}$ Department \\ of Medical Informatics, University of Münster, Münster, ${ }^{e}$ Department of Medicine IV, Hematology and Oncology, \\ University of Halle, Halle, and f Department of Hematology and Oncology, Medical Center Leverkusen, Leverkusen, \\ Germany; ${ }^{9}$ Department of Hematology, Inselspital Bern, Bern, Switzerland
}

\section{Keywords}

Autologous stem cell transplantation - Induction therapy . Melphalan high-dose chemotherapy · Multiple myeloma . Novel compounds · Tandem autologous stem cell transplantation

\begin{abstract}
Within this retrospective single-center study, we analyzed the survival of 320 multiple myeloma (MM) patients receiving melphalan high-dose chemotherapy (HDCT) and either single $(n=286)$ or tandem $(n=34)$ autologous stem cell transplantation (ASCT) from 1996 to 2012. Additionally, the impact of novel induction regimens was assessed. Median follow-up was 67 months, median overall survival (OS) 62 months, median progression-free survival (PFS) 33 months (95\% Cl 27-39), and treatment-related death (TRD) 3\%. Multivariate analysis revealed age $\geq 60$ years $(p=0.03)$ and stage
\end{abstract}

\section{KARGER}

(C) 2017 S. Karger AG, Basel

E-Mail karger@karger.com

www.karger.com/aha
3 according to the International Staging System $(p=0.006)$ as adverse risk factors regarding PFS. Median OS was significantly better in newly diagnosed MM patients receiving induction therapy with novel agents, e.g., bortezomib, thalidomide, or lenalidomide, compared with a traditional regimen ( 69 vs. 58 months; $p=0.01$ ). More patients achieved at least a very good partial remission in the period from 2005 to 2012 than from 1996 to 2004 ( 65 vs. 30\%; $p<0.001$ ), with a longer median OS in the later period (71 vs. 52 months, $p=0.027$ ). In conclusion, our analysis confirms HDCT-ASCT as an effective therapeutic strategy in an unselected large myeloma patient cohort with a low TRD rate and improved prognosis due to novel induction strategies.

(c) 2017 S. Karger AG, Basel

Martin H. Kropff, Nils H. Thoennissen, and Wolfgang E. Berdel contributed equally and should be considered senior authors.
Gabriela B. Thoennissen, MD

Hubertus Wald University Cancer Center University Medical Center Hamburg-Eppendorf Martinistrasse 52, DE-20251 Hamburg (Germany)

E-Mail g.thoennissen@uke.de 


\section{Introduction}

Particularly for younger and fit patients with newly diagnosed multiple myeloma (NDMM), the melphalan high-dose chemotherapy (HDCT) with autologous stem cell transplantation (ASCT) regimen is superior to conventional chemotherapy regarding response rate, eventfree survival (EFS), and in part also overall survival (OS). Thus, HDCT-ASCT established as standard multiple myeloma (MM) therapy [1-4]. Together with other B-cell lymphomas, it remains the most frequent indication for ASCT worldwide $[5,6]$.

Nevertheless, median duration of response after HDCT-ASCT is documented as less than 3 years, and the majority of patients experience relapse [7]. Particularly for older patients and patients with refractory myeloma, ASCT failed to show significant advantage concerning survival $[8,9]$. Furthermore, tandem ASCT with 2 successive high-dose melphalan regimens within 6 months (preferably within 3) was introduced [10-13].

Starting in the late 1990s, treatment of patients with MM improved with regard to survival upon the introduction of new drugs, including the proteasome inhibitor bortezomib, the immunomodulatory drug thalidomide, and their respective second-generation compounds, e.g., lenalidomide. These novel therapies were first applied to NDMM, refractory, and/or relapsed MM (RRMM) patients [14-22]. Later, they were also used as part of preparatory regimens before ASCT and as part of consolidation and/or maintenance therapy [23-27]. Besides, the use of these novel drugs as part of maintenance therapy following melphalan HDCT-ASCT was shown to improve EFS and OS in case of thalidomide and progression-free survival (PFS) as well as EFS in case of lenalidomide, respectively [28-30]. Recently, the 3-drug combination of lenalidomide, bortezomib, and dexamethasone (RVD) as induction and consolidation with ASCT followed by maintenance therapy with lenalidomide resulted in convincing estimated 3-year PFS of $77 \%$ and 3 -year OS of $100 \%$ [31].

In order to review the efficacy and toxicity for all myeloma patients treated in the Department of Hematology and Oncology at the University of Münster Hospital with single or tandem ASCT without selection criteria for specific studies, we conducted a retrospective analysis in the period from 1996 to 2012. Additionally, we studied the impact of induction therapy containing novel compounds on the outcome of myeloma patients receiving ASCT in our Department.
Table 1. Patient characteristics at diagnosis: entire cohort

\begin{tabular}{|c|c|c|}
\hline Entire cohort $(n=320)$ & $n$ & $\%$ \\
\hline Male & 191 & 60 \\
\hline Female & 129 & 40 \\
\hline \multicolumn{3}{|l|}{ Multiple myeloma type } \\
\hline Unavailable & 2 & $<1$ \\
\hline Available & 318 & 99 \\
\hline $\operatorname{IgG} \kappa$ & 127 & 40 \\
\hline $\operatorname{IgG} \lambda$ & 54 & 17 \\
\hline $\operatorname{Ig} A \kappa$ & 29 & 9 \\
\hline $\operatorname{IgA} \lambda$ & 53 & 17 \\
\hline $\operatorname{IgD} \kappa$ & 1 & $<1$ \\
\hline$\kappa$ & 31 & 10 \\
\hline$\lambda$ & 17 & 5 \\
\hline Nonsecretory & 4 & 1 \\
\hline Biclonal & 2 & $<1$ \\
\hline \multicolumn{3}{|l|}{ Durie-Salmon stage } \\
\hline Unavailable & 48 & 15 \\
\hline Available & 272 & 85 \\
\hline IA & 23 & 8 \\
\hline IB & 5 & 2 \\
\hline IIA & 26 & 10 \\
\hline IIB & 7 & 3 \\
\hline IIIA & 162 & 59 \\
\hline IIIB & 49 & 18 \\
\hline \multicolumn{3}{|l|}{ ISS stage } \\
\hline Unavailable & 108 & 34 \\
\hline Available & 212 & 66 \\
\hline 1 & 90 & 42 \\
\hline 2 & 80 & 38 \\
\hline 3 & 42 & 20 \\
\hline \multicolumn{3}{|c|}{ Cytogenetic risk stratification at diagnosis } \\
\hline Unavailable & 193 & 60 \\
\hline Available & 127 & 40 \\
\hline Standard risk & 101 & 80 \\
\hline Intermediate risk & 7 & 5 \\
\hline High risk & 19 & 15 \\
\hline
\end{tabular}

The median age of the patients was 56 years (range: $35-74)$. ISS, International Staging System; available, detailed information available.

\section{Patients and Methods}

Data of myeloma patients receiving single or tandem ASCT following melphalan HDCT were available for the period from October 1996 to August 2012, which allowed us to analyze 320 consecutive patients altogether retrospectively. Eligibility criteria for ASCT for these patients were age $\leq 75$ years, a suitable Eastern Cooperative Oncology Group performance status, and the lack of significant comorbidities or multiple organ dysfunctions. Patients with cytogenetic high-risk constellation or an insufficient hematological response after the first ASCT (partial remission, PR, or worse) were offered the tandem ASCT modality. Single ASCT was applied to 286 and tandem ASCT to 34 patients. The characteris-
Thoennissen et al. 
Table 2. Myeloma therapies and hematological response

\begin{tabular}{|c|c|c|c|}
\hline & $\begin{array}{l}\text { Entire cohort } \\
(n=320)\end{array}$ & $n$ & $\%$ \\
\hline \multicolumn{4}{|l|}{ Induction therapies } \\
\hline \multirow[t]{6}{*}{ Number/patient } & Unavailable & 41 & 13 \\
\hline & Available & 279 & 87 \\
\hline & 1 & 176 & 63 \\
\hline & 2 & 83 & 30 \\
\hline & 3 & 18 & 6 \\
\hline & 5 & 2 & $<1$ \\
\hline \multirow[t]{4}{*}{ Type/patient } & Unavailable & 40 & 12 \\
\hline & Available & 280 & 88 \\
\hline & Traditional & 156 & 56 \\
\hline & Novel & 124 & 44 \\
\hline \multirow[t]{4}{*}{ Novel therapy types ${ }^{1}$} & Thalidomide based & 9 & 3 \\
\hline & Bortezomib based & 113 & 40 \\
\hline & Lenalidomide based & 12 & 4 \\
\hline & VTD & 2 & $<1$ \\
\hline \multicolumn{4}{|l|}{ Therapies after ASCT } \\
\hline \multirow[t]{4}{*}{ Consolidation } & Unavailable & 156 & 49 \\
\hline & Available & 164 & 51 \\
\hline & Yes & 15 & 9 \\
\hline & No & 149 & 91 \\
\hline Consolidation & Bortezomib & 12 & 7 \\
\hline \multirow[t]{4}{*}{ Maintenance/patient } & Unavailable & 129 & 40 \\
\hline & Available & 191 & 60 \\
\hline & Yes & 55 & 29 \\
\hline & No & 136 & 71 \\
\hline \multirow[t]{5}{*}{ Maintenance, total } & Interferon & 44 & 23 \\
\hline & Lenalidomide based & 5 & 3 \\
\hline & Dexamethasone based & 1 & $<1$ \\
\hline & Bortezomib based & 2 & 1 \\
\hline & Thalidomide based & 6 & 3 \\
\hline \multirow[t]{4}{*}{ Salvage chemotherapy } & Unavailable & 165 & 52 \\
\hline & Available & 155 & 48 \\
\hline & Yes & 138 & 89 \\
\hline & No & 17 & 11 \\
\hline \multirow{2}{*}{$\begin{array}{l}\text { Type of salvage } \\
\text { therapy/patient }\end{array}$} & Traditional & 36 & 26 \\
\hline & Novel & 102 & 74 \\
\hline \multirow[t]{7}{*}{ Salvage transplant } & Unavailable & 183 & 57 \\
\hline & Available & 137 & 43 \\
\hline & Yes & 26 & 19 \\
\hline & No & 111 & 81 \\
\hline & ASCT & 16 & 62 \\
\hline & Allogeneic & 9 & 35 \\
\hline & Autologous-allogeneic & 1 & 4 \\
\hline
\end{tabular}

tics of the patients are given in Table 1 as well as in online supplementary Tables 1 and 2 (for all online suppl. material, see www. karger.com/doi/10.1159/000463534). All patients provided written informed consent before therapy. This retrospective evaluation has been approved by the Ethics Board of the Faculty of Medicine at the Westfälische Wilhelms University of Münster and the Physicians Chamber of Westfalen-Lippe (permit No. 2014-039-f-N).

Entire cohort $(n=320)$

Hematological response Before ASCT

$\begin{array}{ll}\text { Before ASCT } & \text { Unavailable } \\ \text { Available } \\ \text { sCR } \\ \text { CR } \\ \text { VGPR } \\ \text { PR } \\ \text { SD } \\ \text { PD }\end{array}$

After ASCT

$($ day +100$)$

Unavailable

Available

sCR

CR

VGPR

PR

SD

$\mathrm{PD}$

At the last follow-up

Unavaila
Available
sCR
CR
VGPR
PR
SD
PD

Available, detailed information available; CR, complete remission; sCR, stringent CR; PR, partial remission; VGPR, very good PR; SD, stable disease; PD, progressive disease; VTD, Velcade/thalidomide/dexamethasone; ASCT, autologous stem cell transplantation.

${ }^{1}$ Types of novel induction therapies $(n=136)$ in total (patient independent).

Treatment response was evaluated according to the International Myeloma Working Group criteria [32]. The objectives of our study were to investigate OS, PFS, hematological response, and treatment-related death (TRD).

Four patients were participating in an autologous/allogeneic sequential transplantation treatment study [33]. After ASCT and upon relapse/progression, patients were offered to participate in several rescue studies, e.g., with the triple angiokinase inhibitor BIBF 1120 [34], the receptor tyrosine kinase inhibitor SU6668 [35], or other novel drugs [unpubl. data] [16, 19, 20]. Cytogenetic risk stratification by conventional cytogenetics and/or FISH analysis from bone marrow at diagnosis was available in 127 patients (40\%). Patients who had 1 or more of the following abnormalities $-\mathrm{t}(4 ; 14), \mathrm{t}(14 ; 16), \mathrm{t}(14 ; 20), \operatorname{del}(17 \mathrm{p})$, and/or gain of $1 \mathrm{q} 21$ were categorized as high risk [36]. Patients with $t(11 ; 14)$ were considered of intermediate risk. All other karyotypes, including $13 \mathrm{q}$ deletion and cases without cytogenetic abnormalities by chromosome banding/FISH were considered standard risk. 
Table 3. Multi- and univariate Cox proportional-hazards regression of prognostic factors for progression-free (PFS) and overall survival (OS)

\begin{tabular}{|c|c|c|c|c|}
\hline & Covariate & $\begin{array}{l}p \\
\text { value }^{1}\end{array}$ & HR & $95 \% \mathrm{CI}$ \\
\hline \multicolumn{5}{|c|}{$\begin{array}{l}\text { Multivariate Cox proportional-hazards regression with } \\
\text { backward likelihood ratio variable }\end{array}$} \\
\hline \multirow[t]{4}{*}{ PFS } & Age $(\leq 60 \text { vs. }>60 \text { years })^{2}$ & 0.030 & 1.922 & $1.1-3.5$ \\
\hline & ISS stage & 0.023 & & \\
\hline & ISS 1 vs. ISS 2 & 0.107 & & \\
\hline & ISS 1 vs. I & 0.006 & 2.599 & $1.3-5.1$ \\
\hline OS & SG-1 vs. SG-2 after ASCT & 0.021 & 2.8 & $1.2-7.0$ \\
\hline \multicolumn{5}{|c|}{ Univariate Cox proportional-hazards regression } \\
\hline \multirow[t]{11}{*}{ PFS } & Age $(\leq 60 \text { vs. }>60 \text { years })^{2}$ & 0.011 & 1.562 & $1.1-2.2$ \\
\hline & Gender (male vs. female) & 0.518 & & \\
\hline & Cytogenetic risk & 0.037 & & \\
\hline & (SR vs. IR) & 0.269 & & \\
\hline & ( $S R$ vs. high risk) & 0.015 & 2.398 & $1.2-4.9$ \\
\hline & $\beta_{2}-\mathrm{MG}(\leq 3.5$ vs. $>3.5 \mathrm{mg} / \mathrm{L})$ & 0.004 & 1.698 & $1.2-2.4$ \\
\hline & ISS stage & 0.001 & & \\
\hline & ISS 1 vs. ISS 2 & 0.032 & 1.573 & $1.0-2.4$ \\
\hline & ISS 1 vs. ISS 3 & $<0.001$ & 2.425 & $1.5-3.9$ \\
\hline & SG-1 vs. SG-2 before ASCT & 0.156 & & \\
\hline & SG-1 vs. SG-2 after ASCT & 0.630 & & \\
\hline \multirow[t]{2}{*}{ OS } & SG-1 vs. SG-2 before ASCT & 0.007 & 2.303 & $1.3-4.2$ \\
\hline & SG-1 vs. SG-2 after ASCT & 0.001 & 1.967 & $1.3-2.9$ \\
\hline \multicolumn{5}{|c|}{$\begin{array}{l}\text { Adequate information was available for } 238 \text { patients. Reference } \\
\text { categories are in italics. HR, hazard ratio; } 95 \% \text { CI, } 95 \% \text { confidence } \\
\text { interval; ISS, International Staging System; SG, subgroup; SR, stan- } \\
\text { dard risk; IR, intermediate risk. } 38 \text { patients from the single ASCT } \\
\text { cohort were censored at the last contact due to missing data for } \\
\text { survival analysis. } \\
{ }^{1} \text { Wald test } p \text { values adjusted for age and gender. } \\
{ }^{2} \text { Age at diagnosis. }\end{array}$} \\
\hline
\end{tabular}

Detailed information about the procedures of stem cell mobilization and peripheral blood stem cell collection as well as melphalan HDCT and ASCT can be found as online supplementary information 1 .

\section{Statistical Methods}

Statistical analysis was performed with the support of the Statistical Package for Social Sciences (SPSS 22, released 2013, IBM SPSS Statistics for Windows, version 22.0; IBM Corp., Armonk, NY, USA). OS was calculated starting from the day of the first ASCT (day 0) until death from any reason with censoring of patients alive at their last follow-up. PFS in terms of death or progression was measured from the day of ASCT to the day of documented death, progression, or relapse, respectively. PFS for patients being alive and in remission was censored at the last follow-up. TRD was determined as death from any cause other than progression or relapse before day +100 from the last ASCT in patients with a follow-up of at least 100 days after the last ASCT. Thus, patients with a follow-up $<100$ days after ASCT were excluded from TRD anal- ysis. The Fisher exact test was used for categorical variables, and the Mann-Whitney U test was used for continuous variables. OS and PFS were estimated with the Kaplan-Meier method; log-rank tests with a $95 \%$ confidence interval $(95 \% \mathrm{CI})$ were used for comparison of time-dependent outcome measures. $p$ values $<0.05$ were considered as indicating statistically significant differences. $\mathrm{Me}$ dian follow-up was calculated by reverse censoring.

Potent covariates with impact on OS and PFS were calculated by Cox regression analysis with respective hazard ratios (HR) and Wald test $p$ values adjusted for age and gender. For Cox regression analysis of PFS with backward likelihood ratio variable selection, 82 patients of the entire cohort with available data on the chosen covariates age at diagnosis ( $\leq 60$ vs. $>60$ years), gender, cytogenetic risk, International Staging System (ISS) stage, and induction therapy have been included. For Cox regression analysis of OS without variable selection, 95 patients of the entire cohort with complete data have been included.

\section{Results}

The baseline characteristics of the entire cohort as well as detailed information about the single and tandem ASCT groups are listed in Table 1 as well as in online supplementary Tables 1 and 2. Overall, a total of 320 patients with symptomatic MM (191 males and 129 females; male female ratio 1.5) were evaluated for this retrospective analysis. The median age at diagnosis was 57 years (range 35-74), and the median age at ASCT was 58 years (range $35-75)$. TRD was $3 \%$. The majority of the patients $(n=$ $162 ; 59 \%)$ was diagnosed with Durie-Salmon stage IIIA (Table 1). ISS 1 was most frequent ( $n=90$ patients; $42 \%$ ) followed by ISS 2 ( $n=80$ patients; $38 \%$ ). Before ASCT, $19 \%$ of the patients $(n=51)$ were in stable or progressive disease (Table 2).

\section{Patient Outcome with regard to Prognostic Factors}

At a median follow-up of 67 months (95\% confidence interval, 60.0-74.0), the median OS and PFS for the entire cohort were 62 months (95\% CI 51.3-72.7) and 33 months (95\% CI 27.0-39.0), respectively. Five years after ASCT, OS was 51\% (SE 3.6) and PFS was 27\% (SE 3.4). There was no significant difference between males and females with regard to OS and PFS (Table 3, and data not shown). Patients $>60$ years at the time of ASCT had a significantly worsened PFS as compared to those aged $\leq 60$ years (median 26 vs. 41 months, $p<0.001$; Fig. 1a), whereas there was only a nonsignificant trend for OS (median 49 vs. 68 months; $p=0.074$; data not shown). There was no significant difference in survival between patients aged $\leq 65$ and $>65$ years at the time of ASCT (data not shown). Age $\leq 60$ versus $>60$ years at diagnosis was an independent 


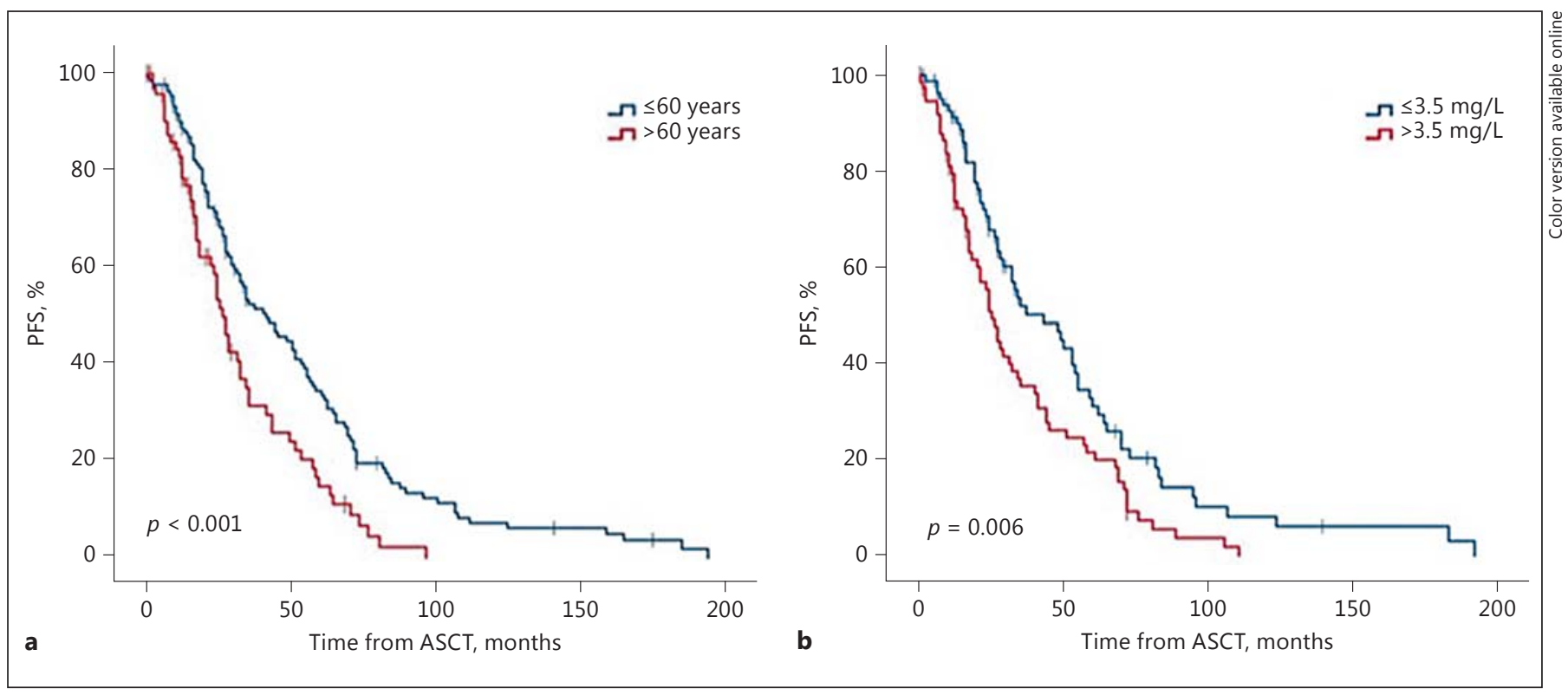

Fig. 1. Analyses of prognostic factors for progression-free survival (PFS) in relation to age $\leq 60$ vs. $>60$ years at autologous stem cell transplantation (ASCT) (a) and $\beta_{2}$-microglobulin $\leq 3.5$ vs. 3.5 $\mathrm{mg} / \mathrm{L}$ at diagnosis (b), as well as depending on cytogenetic risk stratification at diagnosis $(\mathbf{c})$.

prognostic factor for PFS in univariate $(p=0.011$, HR $1.562,95 \%$ CI 1.1-2.2) as well as in multivariate analysis $(p=0.030$, HR 1.922, 95\% CI 1.1-3.5; Table 3). ISS 3 at the time of diagnosis was significantly associated with worse PFS compared to ISS 1 and ISS 2 (PFS for ISS $1=$ 48 months, ISS $2=27$ months, and ISS $3=17$ months; $p$ $=0.002$; further data not shown) and proved to be an independent prognosticator for PFS in multivariate analysis (ISS 1 vs. ISS $3 ; p=0.006$, HR 2.599, 95\% CI 1.3-5.1; Table 3). Patients with an initial $\beta_{2}$-microglobulin $\left(\beta_{2^{-}}\right.$ MG) level $>3.5 \mathrm{mg} / \mathrm{L}$ had a significantly shorter PFS than

patients with a $\beta_{2}-\mathrm{MG} \leq 3.5 \mathrm{mg} / \mathrm{L}$ ( 25 vs. 43 months; $p=$ 0.006 ; Fig. 1b). The level of $\beta_{2}-\mathrm{MG}$ ( $\leq 3.5$ vs. $>3.5 \mathrm{mg} / \mathrm{L}$ ) was a predictor in univariate but not in multivariate analysis ( $p=0.004$, HR 1.698, 95\% CI 1.2-2.4; Table 3). Cytogenetic risk stratification had no significant influence on OS, but high risk was significantly associated with inferior PFS as compared to intermediate risk and standard risk (median 17 vs. 21 vs. 32 months; $p=0.018$; Fig. 1c). High risk versus standard risk was also an independent adverse factor for PFS ( $p=0.015$; HR 2.398, 95\% CI $1.2-$ 4.9; Table 3) in univariate but not in multivariate analysis. 


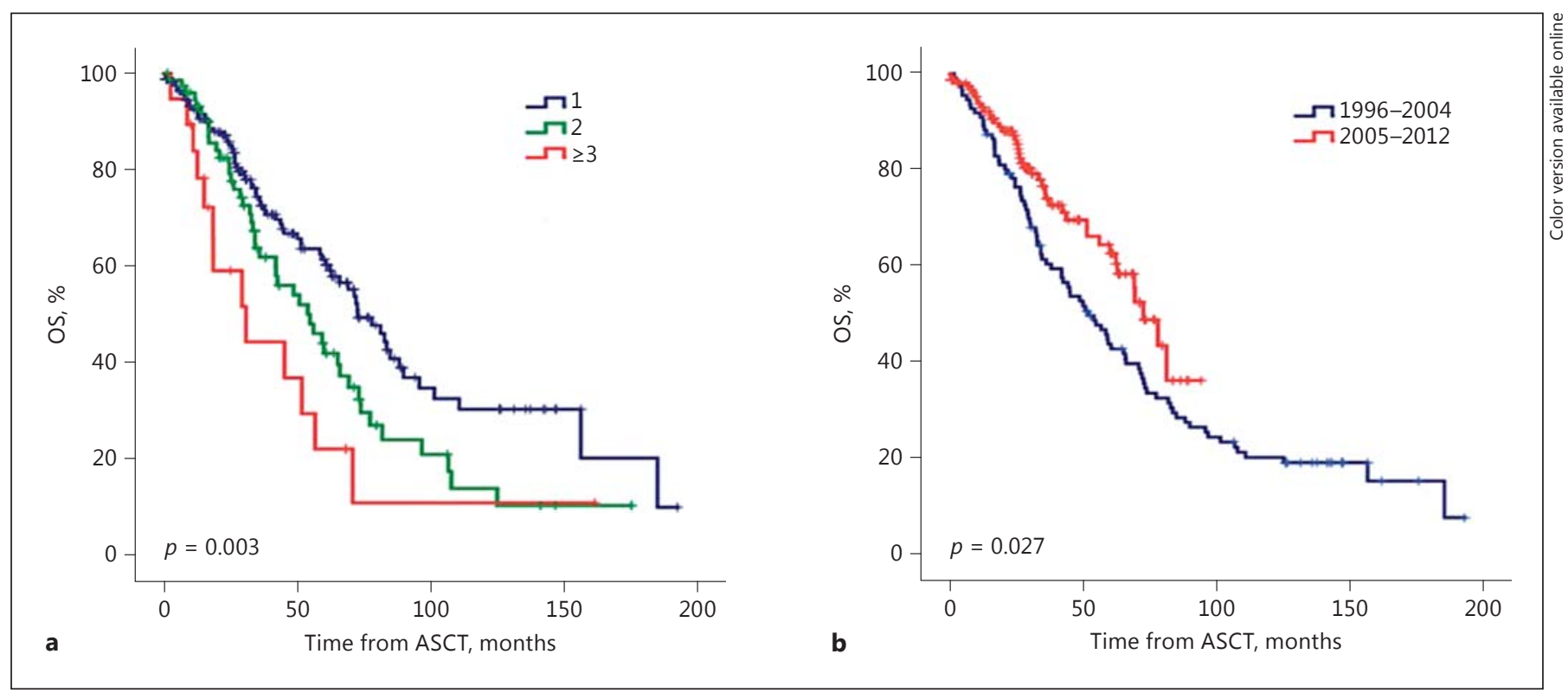

Fig. 2. Overall survival (OS) according to the number of induction therapies (a) and the time of autologous stem cell transplantation (ASCT) (b). a OS of myeloma patients who received 1, 2, or $\geq 3$ induction regimens. b OS of myeloma patients receiving ASCT within 2 time periods: 1996-2004 and 2005-2012.

Survival according to the Number of Induction

Regimes in Combination with Melphalan

HDCT-ASCT

Patients received 1-5 induction regimens before ASCT, whereby $63 \%(n=176)$ of them received only 1 induction regimen (Table 2). Patients with 1 induction regimen showed significantly better median OS than patients with 2 or $\geq 3$ induction regimens ( 72 months, $95 \%$ CI 59.5-84.6; vs. 54 months, $95 \%$ CI 35.9-72.6; vs. 30 months, 95\% CI 9.5-74.8; $p=0.003$; Fig. 2a). To evaluate a possible effect of changing therapeutic and ASCT strategies over time, we divided the entire cohort according to 2 time periods, one from 1996 to 2004 and the other from 2005 to 2012. Indeed, median OS was significantly better for myeloma patients treated in the later period (20052012) with 71 versus 52 months in patients treated from 1996 to 2004 ( $p=0.027$; Fig. 2b).

\section{Impact of Novel Myeloma Therapies in Combination with Melphalan HDCT-ASCT}

As the entire cohort was treated over a time period of approximately 16 years (1996-2012), induction therapy consisted mainly of "traditional" regimens, e.g., the Alexanian protocol melphalan/prednisone (MP), idarubicin/dexamethasone (ID), or vincristine/doxorubicin/ dexamethasone (VAD) in the first half of this period, and mainly of the "novel" therapies based on bortezomib, thalidomide, and/or lenalidomide in addition to corticosteroids in the second half of the period (Table 2). Based on our data and in accordance with respective approval dates of the novel compounds, the novel regimens were mainly applied after the year 2000 (data not shown).

In order to look for the impact of induction therapy with these novel compounds followed by melphalan HDCT-ASCT, we compared OS of NDMM patients who received either a traditional regimen or a novel regimen before ASCT. Follow-up data were available for $n=245$ patients. Median OS was significantly worse in NDMM patients $(n=158)$ receiving induction therapy with a traditional regimen than in NDMM patients $(n=87)$ treated with a novel compound (58 months, 95\% CI 47.2-68.7; vs. 69 months, 95\% CI not available; $p=0.01$; Fig. 3). There was no significant impact on PFS though.

\section{Patient Characteristics at ASCT}

Comparing the results of patients receiving single versus tandem ASCT, we refrained from statistical analyses of survival due to a selection bias of patients for the different transplant approaches (mainly patients with poor response to induction therapy were candidates for tandem ASCT), and due to the limited number of patients 


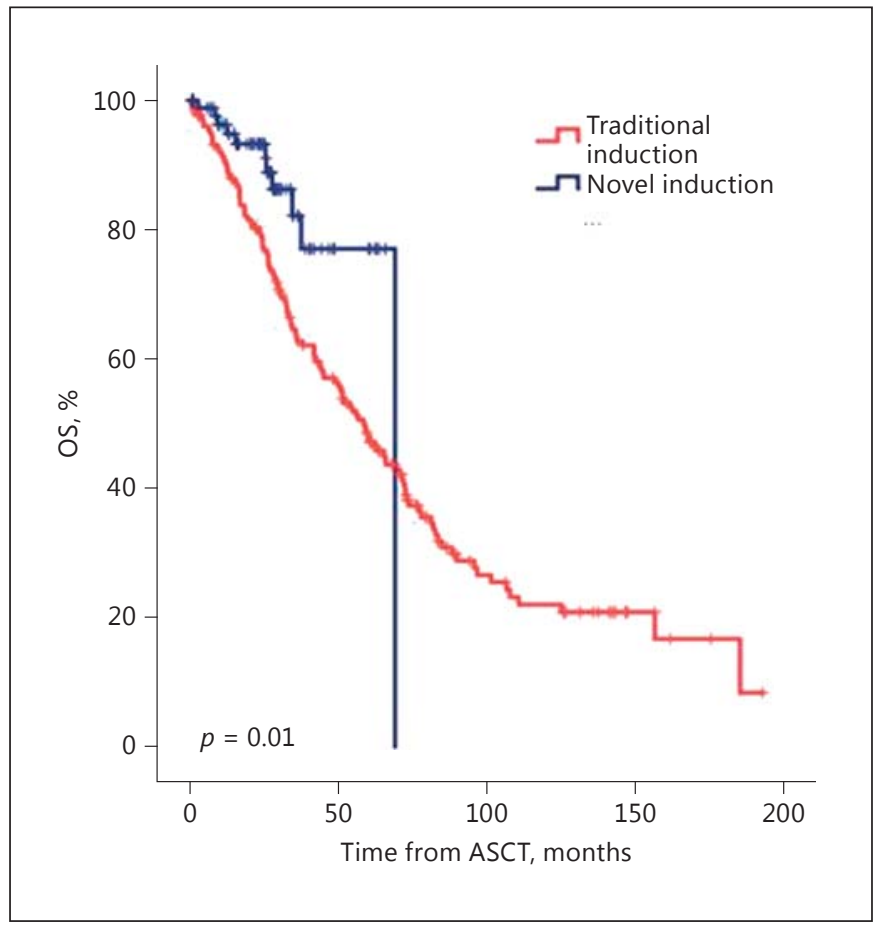

Fig. 3. Overall survival (OS) depending on traditional versus novel induction therapies. OS of newly diagnosed multiple myeloma patients who received only first-line induction either with a traditional or a novel regimen before autologous stem cell transplantation (ASCT).

who underwent tandem ASCT $(n=34)$. Thus, we rather focused on the descriptive analysis of treatments and response rates in both groups, which can be found as online supplementary Tables 1 and 2.

\section{Survival in Relation to Hematological Response}

Hematological response rates of the entire cohort before and after ASCT are depicted in Table 1. In order to draw conclusions about survival in relation to hematological response, we divided the entire cohort into subgroups (SG). Patients with a very good PR (VGPR) or better were assigned to SG-1, whereas patients with a PR or worse were allocated to SG-2. Patients in SG-1 before ASCT $(n=66)$ showed a significant advantage in OS compared to the 204 patients in SG-2 before ASCT (median 72 vs. 54 months; $p=0.006$; further details not shown), whereas no significant impact on PFS was observed. Approximately $41 \%$ of the patients $(n=130)$ reached a VGPR or better $\geq 100$ days after ASCT. In accordance with previous literature [37], patients responding to ASCT with VGPR or better (SG-1 after ASCT, $n=130$ )

High-Dose Melphalan in Multiple

Myeloma $\geq 100$ days after ASCT showed a significant benefit in median OS compared to patients responding with PR or worse (SG-2 after ASCT, $n=127$ ) with 89 versus 53 months $(p=0.001)$. Again, there was no significant influence on PFS. SG-1 versus SG-2 before ASCT was a significant prognostic factor for OS in univariate analysis though ( $p=0.007$, HR 2.303, 95\% CI 1.3-4.2; Table 3). After ASCT, SG-1 versus SG-2 was a significant prognostic factor for OS in both univariate $(p=0.001$, HR 1.967, 95\% CI 1.3-2.9, respectively) and multivariate analysis ( $p=0.021$, HR 2.860, 95\% CI 1.2-7.0; Table 3). Additionally, we analyzed the distribution of both SGs within the 2 time periods (1996-2004 and 2005-2012). The percentage of patients with at least VGPR or better was significantly higher in the second period with 65\% (99 of 152 patients) as compared to $30 \%$ (31 of 105 patients) in the first period $(p<0.001)$.

\section{Therapy after ASCT}

The regimens used over time for treatment after ASCT, including consolidation, maintenance, and salvage therapy, are shown in Table 2. For salvage therapy, $74 \%$ of the patients (102 of 138) received treatment with novel compounds (Table 2). Decisions for/against intervention after ASCT were mainly based on benefit/ risk estimation according to the disease history of the individual patient and were influenced by available data over the time period of observation of this cohort. In some patients, they were determined by the study protocol.

\section{Discussion}

Here, we present a retrospective analysis of 320 myeloma patients treated with ASCT following melphalan HDCT in the period from 1996 to 2012. As we aimed to investigate an unselected patient cohort, patients were treated outside clinical trials and some within different study protocols. Thus, they should not be included in future meta-analyses not based on single patient record forms to prevent multiple assessments of individuals.

The median PFS and OS observed in this analysis are comparable to those observed in large prospective trials on ASCT in myeloma patients [2-4], and our results corroborate the efficacy of HDCT-ASCT with a low TRD rate of $3 \%$.

In accordance with the previous literature [37, 38], patients in our cohort responding to ASCT with a good remission (SG-1 after ASCT) showed a significantly better 
OS as compared to SG-2 patients (median 89 vs. 53 months, $p=0.001$ ). Indeed, the Royal Marsden group suggested that patients with VGPR or better after the first ASCT should not approach tandem transplant but rather continue with maintenance chemotherapy and undergo salvage transplantation in case of progression [39]. This is currently being studied in a randomized design by the German Study Group on Multiple Myeloma DSMM XIV trial.

For myeloma patients, age was demonstrated to be a crucial prognostic factor concerning survival $[24,25]$. In our analysis, patients $>60$ years at the time of ASCT had a worse PFS in comparison to younger patients (26 vs. 41 months, $p<0.001$ ), whereas OS differences were not significant. In general, $>60 \%$ of patients with $\mathrm{MM}$ are $>65$ years at diagnosis, with a median of 70 years [40]. Even though ASCT and novel compounds such as bortezomib, lenalidomide, and thalidomide markedly improved survival of myeloma patients, this improvement was age specific $[24,25]$. In a report of the European Myeloma Network, the 5-year relative survival of patients $<50$ years at diagnosis was $45 \%$ in the 1990 s and rose to $57 \%$ in 2002 . In contrast, survival increased by only $5 \%$ in patients $>60$ years, and almost no improvement was seen in patients $>70$ years [41]. Thus, application of ASCT to older patients should be considered cautiously and based on individual patient data.

We were able to show that myeloma patients with only 1 induction regimen before ASCT had a better OS than patients with 2 or $\geq 3$ induction regimens (median 72 vs. 54 months vs. 30 months; $p=0.003$ ). This may be explained by the fact that patients who were receiving $>1$ induction regimen before HDCT-ASCT were poor responders to the first induction therapy and had per se a worse outcome than patients proceeding to melphalan HDCT-ASCT after only 1 induction regimen.

In our single-center analysis, NDMM patients treated with traditional regimens including $\mathrm{MP}, \mathrm{CD}$, ID, and VAD as part of the first induction therapy before melphalan HDCT-ASCT had an inferior OS as compared to patients treated with the novel compounds (median 58 vs. 69 months, $p=0.01$ ). As these novel myeloma drugs, especially lenalidomide and bortezomib, were mainly applied in the new millennium for induction therapy as well as salvage therapy, this could explain why patients from our cohort treated in the period from 2005 to 2012 had a better OS than patients treated from 1996 to 2004. Improvements in microbiological analysis, antibiotic regimens, and other developments in supportive care in recent years may also have contributed to this survival advantage in the later period.
Randomized trials prospectively compared the outcome of NDMM patients treated with the older drugs versus the novel regimens as part of combined induction therapy followed by ASCT and have shown improved response rates and prolonged PFS upon the use of the novel therapies, e.g. bortezomib/dexamethasone and bortezomib/thalidomide/dexamethasone. In the IFM 2005-01 study, for example, bortezomib/dexamethasone induction was superior to vincristine/Adriamycin/dexamethasone before and after ASCT [42]. Also, the randomized phase 3 PETHEMA/GEM study showed that induction with the triplet vincristine/Adriamycin/dexamethasone resulted in better response rates before and after ASCT and an improved PFS than thalidomide/dexamethasone or conventional chemotherapy with added bortezomib [43]. Further randomized trials are necessary to evaluate the long-term effects of these novel compounds with and without consecutive ASCT. Nevertheless, these studies were prospective, including an intention-to-treat analysis focusing on induction therapy, whereas this report is a retrospective as-treated analysis and only included patients who underwent ASCT and who, in part, also received salvage therapy with the novel compounds.

In conclusion, melphalan HDCT-ASCT remains the gold standard for the treatment of myeloma patients. However, the most prominent outcome of this retrospective analysis of our complete monocenter patient cohort is that no survival plateaus could be observed, indicating that this approach does not have a curative potential. This is also in agreement with several other trials [7-9] and underlines the urgent medical need for further research on drugs affecting additional targets. Novel compounds such as the immunomodulatory drug pomalidomide, the next-generation proteasome inhibitors carfilzomib and ixazomib, panobinostat, a pan-histone deacetylase inhibitor, and the monoclonal antibodies elotuzumab and daratumumab already show promising results in the treatment of myeloma patients [44-49].

\section{Disclosure Statement}

The authors declare that they have no conflicts of interest.
Thoennissen et al. 


\section{References}

1 Barlogie B, Gahrton G: Bone marrow transplantation in multiple myeloma. Bone Marrow Transplant 1991;7:71-79.

2 Child JA, Morgan GJ, Davies FE, Owen RG, Bell SE, Hawkins K, Hawkins K, Brown J, Drayson MT, Selby PJ: Medical Research Council Adult Leukaemia Working Party. Adult Leukaemia Working Party. High-dose chemotherapy with hematopoietic stem-cell rescue for multiple myeloma. N Engl J Med 2003;348:1875-1883.

3 Attal M, Harousseau JL, Stoppa AM, Sotto JJ, Fuzibet JG, Rossi JF, Casassus P, Maisonneuve $\mathrm{H}$, Facon $\mathrm{T}$, Ifrah $\mathrm{N}$, Payen $\mathrm{C}$, Bataille $\mathrm{R}$ : A prospective, randomized trial of autologous bone marrow transplantation and chemotherapy in multiple myeloma. Intergroupe Francais du Myelome. N Engl J Med 1996; 335:91-97.

4 Lenhoff S, Hjorth M, Holmberg E, Turesson I, Westin J, Nielsen JL, Wislöff F, Brinch L, Carlson K, Carlsson M, Dahl IM, Gimsing P, Hippe E, Johnsen HE, Lamvik J, Löfvenberg E, Nesthus I, Rödjer S: Impact on survival of high-dose therapy with autologous stem cell support in patients younger than 60 years with newly diagnosed multiple myeloma: a population-based study. Nordic Myeloma Study Group. Blood 2000;95:7-11.

5 Copelan EA: Hematopoietic stem-cell transplantation. N Engl J Med 2006;354:18131826.

6 Gratwohl A: Activity survey and historical perspective of autologous stem cell transplantation in Europe. Semin Hematol 2007;44: 220-226.

7 Attal M, Harousseau JL, Facon T, Guilhot F, Doyen C, Fuzibet JG, Monconduit M, Hulin C, Caillot D, Bouabdallah R, Voillat L, Sotto JJ, Grosbois B, Bataille R; InterGroupe Francophone du Myélome: Single versus double autologous stem-cell transplantation for multiple myeloma. N Engl J Med 2003;349:24952502.

8 Fermand J-P, Ravaud P, Katsahian S, Divine M, Leblond V, Dreyfus F, Macro M, Arnulf B, Royer B, Mariette X, Pertuiset E, Belanger C, Janvier M, Chevret S, Brouet JC, Ravaud P; Group Myelome-Autogreffe: High-dose therapy (HDT) and autologous blood stem cell (ABSC) transplantation versus conventional treatment in multiple myeloma (MM): results of a randomized trial in 190 patients 55 to 65 years of age (abstract 1754). Blood 1999; 94(suppl 1):396a.

9 Bladé J, Rosinol L, Sureda A, Ribera JM, DiazMediavilla J, Garcia-Larana J, Mateos MV, Palomera L, Fernandez-Calvo J, Marti JM, Giraldo P, Carbonell F, Callis M, Trjillo J, Gardella S, Moro MJ, Barez A, Soler A, Font L, Fontanillas M, San Miguel J, Programa para el Estudio de la Terapeutica en Hemopatia Maligna (PETHEMA): High-dose therapy in- tensification compared with continued standard chemotherapy in multiple myeloma patients responding to the initial chemotherapy: long-term results from a prospective randomized trial from the Spanish cooperative group PETHEMA. Blood 2005; 106:3755-3759.

10 Harousseau JL, Milpied N, Laporte JP, Collombat P, Facon T, Tigaud JD, Casassus P, Guilhot F, Ifrah N, Gandhour C: Double-intensive therapy in high-risk multiple myeloma. Blood 1992;79:2827-2833.

11 Vesole DH, Barlogie B, Jagannath S, Cheson B, Tricot G, Alexanian R, Crowley J: Highdose therapy for refractory multiple myeloma: improved prognosis with better supportive care and double transplants. Blood 1994; 84:950-956.

12 Barlogie B, Jagannath S, Desikan KR, Mattox S, Vesole D, Siegel D, Tricot G, Munshi N, Fassas A, Singhal S, Mehta J, Anaissie E, Dhodapkar D, Naucke S, Cromer J, Sawyer J, Epstein J, Spoon D, Ayers D, Cheson B, Crowley $\mathrm{J}$ : Total therapy with tandem transplants for newly diagnosed multiple myeloma. Blood 1999;93:55-65.

13 Björkstrand B: European Group for Blood and Marrow Transplantation Registry studies in multiple myeloma. Semin Hematol 2001;3: 219-225.

14 Singhal S, Mekta J, Desikan R, Ayers D, Roberson P, Eddlemon P, Munshi N, Anaissie E, Wilson C, Dhodaphar M, Zeldis J, Barlogie B: Antitumor activity of thalidomide in refractory multiple myeloma. N Engl J Med 1999; 34:1565-1571.

15 Richardson PG, Schlossman RL, Weller E, Hideshima T, Mitsiades C, Davies F, LeBlanc R, Catley LP, Doss D, Kelly K, McKenney M, Mechlowicz J, Freeman A, Deocampo R, Rich R, Ryoo JJ, Chauhan D, Balinski K, Zeldis J, Anderson KC: Immunomodulatory drug CC5013 overcomes drug resistance and is well tolerated in patients with relapsed multiple myeloma. Blood 2002;100:3063-3067.

16 Kropff MH, Lang N, Bisping G, Dominé N, Innig G, Hentrich M, Mitterer M, Südhoff T, Fenk R, Straka C, Heinecke A, Koch OM, Ostermann H, Berdel WE, Kienast J: Hyperfractionated cyclophosphamide in combination with pulsed dexamethasone and thalidomide (HyperCDT) in primary refractory or relapsed multiple myeloma. Br J Haematol 2003;122:607-616.

17 Richardson PG, Barlogie B, Berenson J, Singhal S, Jagannath S, Irwin D, Rajkumar SV, Srkalovic G, Alsina M, Alexanian R, Siegel D, Orlowski RZ, Kuter D, Limentani SA, Lee S, Hideshima T, Esseltine DL, Kauffman M, Adams J, Schenkein DP, Anderson KC: A phase 2 study of bortezomib in relapsed, refractory myeloma. N Engl J Med 2003;348:2609-2617.

18 Jagannath S, Durie BG, Wolf J, Camacho E, Irwin D, Lutzky J, McKinley M, Gabayan E,
Mazumder A, Schenkein D, Crowley J: Bortezomib therapy alone and in combination with dexamethasone for previously untreated symptomatic multiple myeloma. Br J Haematol 2005;129:776-783.

19 Kropff MH, Bisping G, Wenning D, Volpert S, Tchinda J, Berdel WE, Kienast J: Bortezomib in combination with dexamethasone for relapsed multiple myeloma. Leuk Res 2005; 29:587-590.

20 Kropff M, Bisping G, Schuck E, Liebisch P, Volpert S, Tchinda J, Berdel WE, Kienast J: Bortezomib in combination with intermediate-dose dexamethasone and continuous lowdose oral cyclophosphamide for relapsed multiple myeloma. Br J Haematol 2007;138: 330-337.

21 Kropff M, Liebisch P, Knop S, Weisel K, Wand H, Gann CN, Berdel WE, Einsele H; Deutsche Studiengruppe Multiples Myelom, DSMM: DSMM XI study: dose definition for intravenous cyclophosphamide in combination with bortezomib/dexamethasone for remission induction in patients with newly diagnosed myeloma. Ann Hematol 2009;88: 1125-1130.

22 Richardson PG, Blood E, Mitsiades CS, Jagannath S, Zeldenrust SR, Alsina M, Schlossman RL, Rajkumar SV, Desikan KR, Hideshima T, Munshi NC, Kelly-Colson K, Doss D, McKenney ML, Gorelik S, Warren D, Freeman A, Rich R, Wu A, Olesnyckyj M, Wride K, Dalton WS, Zeldis J, Knight R, Weller E, Anderson $\mathrm{KC}$ : A randomized phase 2 study of lenalidomide therapy for patients with relapsed or relapsed and refractory multiple myeloma. Blood 2006;108:3458-3464.

23 Kristinsson SY, Landgren O, Dickman PW, Derolf AR, Björkholm M: Patterns of survival in multiple myeloma: a population-based study of patients diagnosed in Sweden from 1973 to 2003. J Clin Oncol 2007;25:1993-1999.

24 Brenner H, Gondos A, Pulte D: Recent major improvements in long-term survival of younger patients with multiple myeloma. Blood 2008;111:2521-2526.

25 Schaapveld M, Visser O, Siesling S, Schaar CG, Zweegman S, Vellenga E: Improved survival among younger but not among older patients with multiple myeloma in the Netherlands, a population- based study since 1989 . Eur J Cancer 2010;46:160-169.

26 Kumar SK, Rajkumar SV, Dispenzieri A, Lacy MQ, Hayman SR, Buadi FK, Zeldenrust SR, Dingli D, Russell SJ, Lust JA, Greipp PR, Kyle RA, Gertz MA: Improved survival in multiple myeloma and the impact of novel therapies. Blood 2008;111:2516-2520.

27 Moreau P, Avet-Loiseau H, Harrousseau JL, Attal M: Current trends in autologous stem cell transplantation for myeloma in the era of novel therapies. J Clin Oncol 2011;29:18981906.
High-Dose Melphalan in Multiple

Myeloma
Acta Haematol 2017;137:163-172

DOI: $10.1159 / 000463534$ 
28 Attal M, Harousseau JL, Leyvraz S, Doyen C, Hulin C, Benboubker L, Yakoub Agha I, Bourhis JH, Garderet L, Pegourie B, Dumontet C, Renaud M, Voillat L, Berthou C, Marit G, Monconduit M, Caillot D, Grobois B, Avet-Loiseau H, Moreau P, Facon T; InterGroupe Francophone du Myélome (IFM): Maintenance therapy with thalidomide improves survival in patients with multiple myeloma. Blood 2006;108:3289-3294.

29 Attal M, Lauwers-Cances V, Marit G, Caillot D, Moreau P, Facon T, Stoppa AM, Hulin C, Benboubker L, Garderet L, Decaux O, Leyvraz S, Vekemans MC, Voillat L, Michallet M, Pegourie B, Dumontet C, Roussel M, Leleu X, Mathiot C, Payen C, Avet-Loiseau H, Harousseau JL; IFM Investigators: Lenalidomide maintenance after stem-cell transplantation for multiple myeloma. N Engl J Med 2012; 366:1782-1791.

30 Stewart AK, Trudel S, Bahlis NJ, White D, Sabry W, Belch A, Reiman T, Roy J, Shustik C, Kovacs MJ, Rubinger M, Cantin G, Song K, Tompkins KA, Marcellus DC, Lacy MQ, Sussman J, Reece D, Brundage M, Harnett EL, Shepherd L, Chapman JA, Meyer RM: A randomized phase 3 trial of thalidomide and prednisone as maintenance therapy after ASCT in patients with MM with a quality-oflife assessment: the National Cancer Institute of Canada Clinicals Trials Group Myeloma 10 Trial. Blood 2013;121:1517-1523.

31 Roussel M, Lauwers-Cances V, Robillard N, Hulin C, Leleu X, Benboubker L, Marit G, Moreau P, Pegourie B, Caillot D, Fruchart C, Stoppa AM, Gentil C, Wuilleme S, Huynh A, Hebraud B, Corre J, Chretien ML, Facon T, Avet-Loiseau H, Attal M: Front-line transplantation program with lenalidomide, bortezomib, and dexamethasone combination as induction and consolidation followed by lenalidomide maintenance in patients with multiple myeloma: a phase II study by the Intergroupe Francophone du Myélome. J Clin Oncol 2014;32:2712-2717.

32 Durie BG, Harousseau JL, Miguel JS, Bladé J, Barlogie B, Anderson K, Gertz M, Dimopoulos M, Westin J, Sonneveld P, Ludwig H, Gahrton G, Beksac M, Crowley J, Belch A, Boccadaro M, Cavo M, Turesson I, Joshua D, Vesole D, Kyle R, Alexanian R, Tricot G, Attal M, Merlini G, Powles R, Richardson P, Shimizu K, Tosi P, Morgan G, Rajkumar SV; International Myeloma Working Group: International uniform response criteria for multiple myeloma. Leukemia 2006;20:1467-1473.

33 Gahrton G, Iacobelli S, Björkstrand B, Hegenbart U, Gruber A, Greinix H, Volin L, Narni F, Carella AM, Beksac M, Bosi A, Milone G, Corradini P, Schönland S, Friberg K, van Biezen A, Goldschmidt H, de Witte T, Morris C, Niederwieser D, Garderet L, Kröger N;
EBMT Chronic Malignancies Working Party Plasma Cell Disorders Subcommittee: Autologous/reduced-intensity allogeneic stem cell transplantation vs autologous transplantation in multiple myeloma: long-term results of the EBMT-NMAM2000 study. Blood 2013;20: 5055-5063.

34 Kropff M, Kienast J, Bisping G, Berdel WE, Gaschler-Markefski B, Stopfer P, Stefanic M, Munzert G: An open-label dose-escalation study of BIBF 1120 in patients with relapsed or refractory multiple myeloma. Anticancer Res 2009;29:4233-4238.

35 Martinelli G, Tosi P, Ottaviani E, Soverini S, Tura S: Molecular therapy for multiple myeloma. Haematologica 2001;86:908-917.

36 Rajkumar SV: Multiple myeloma: 2013 update on diagnosis, risk-stratification, and management. Am J Hematol 2013;88:226235.

37 Attal M, Harousseau JL: Randomized trial experience of the Intergroupe Francophone du Myélome. Semin Hematol 2001;38:226-230.

38 Gonsalves WI, Gertz MA, Dispenzieri A, Lacy MQ, Lin Y, Singh PP, Gupta V, Hayman SR, Buadi FK, Dingli D, Kapoor P, McCurdy AR, Kumar SK: Implications of continued response after autologous stem cell transplantation for multiple myeloma. Blood 2013;122: 1746-1749.

39 Sirohi B, Powles R, Singhal S, Treleaven J, Kulkami S, Sankpal S: Second high-dose melphalan autografts for myeloma patients relapsing after one autograft: results equivalent to tandem transplantation (abstract 121). Bone Marrow Transplant 2001;29:(suppl 2): S12.

40 Altekruse SF, Kosary CL, Krapcho M, Neyman N, Aminou R, Waldron W, Ruhl J, Howlader N, Tatalovich Z, Cho H, Mariotto A, Eisner MP, Lewis DR, Cronin K, Chen HS, Feuer EJ, Stinchcomb DG, Edwards BK (eds): SEER Cancer Statistics Review 1975-2007, National Cancer Institute. 2009, Bethesda, http://seer. cancer.gov/csr/1975_2007/.

41 Palumbo A, Bringhen S, Ludwig H, Dimopoulos MA, Bladé J, Mateos MV, Rosiñol L, Boccadoro M, Cavo M, Lokhorst H, Zweegman S, Terpos E, Davies F, Driessen C, Gimsing P, Gramatzki M, Hàjek R, Johnsen HE, Leal Da Costa F, Sezer O, Spencer A, Beksac M, Morgan G, Einsele H, San Miguel JF, Sonneveld P: Personalized therapy in multiple myeloma according to patient age and vulnerability: a report of the European Myeloma Network (EMN). Blood 2011;118:4519-4529.

42 Harousseau JL, Attal M, Avet-Loiseau H, Marit G, Caillot D, Mohty M, Lenain P, Hulin C, Facon T, Casassus P, Michallet M, Maisonneuve $\mathrm{H}$, Benboubker L, Maloisel F, Petillon MO, Webb I, Mathiot C, Moreau P: Bortezomib plus dexamethasone is superior to vin- cristine plus doxorubicin plus dexamethasone as induction treatment prior to autologous stem-cell transplantation in newly diagnosed multiple myeloma: results of the IFM 2005-01 phase III trial. J Clin Oncol 2010;28:4621-4629.

43 Rosiñol L, Oriol A, Teruel AI, Hernández D, López-Jiménez J, de la Rubia J, Granell M, Besalduch J, Palomera L, González Y, Etxebeste MA, Díaz-Mediavilla J, Hernández MT, de Arriba F, Gutiérrez NC, Martín-Ramos ML, Cibeira MT, Mateos MV, Martínez J, Alegre A, Lahuerta JJ, San Miguel J, Bladé J; Programa para el Estudio y la Terapéutica de las Hemopatías Malignas/Grupo Español de Mieloma (PETHEMA/GEM) group: Superiority of bortezomib, thalidomide, and dexamethasone (VTD) as induction pretransplantation therapy in multiple myeloma: a randomized phase 3 PETHEMA/GEM study. Blood 2012;120:1589-1596.

44 Shah JJ, Stadtmauer EA, Abonour R, Cohen $\mathrm{AD}$, Bensinger WI, Gasparetto C, Kaufman JL, Lentzsch S, Vogl DT, Gomes CL, Pascucci N, Smith DD, Orlowski RZ, Durie BG: Carfilzomib, pomalidomide, and dexamethasone (CPD) in patients with relapsed and/or refractory multiple myeloma. Blood 2015;126: 2284-2290.

45 Mikhael JR, Reeder CB, Libby EN, Costa LJ, Bergsagel PL, Buadi F, Mayo A, Nagi Reddy SK, Gano K, Dueck AC, Stewart AK: Phase Ib/ II trial of CYKLONE (cyclophosphamide, carfilzomib, thalidomide and dexamethasone) for newly diagnosed myeloma. Br J Haematol 2015;169:219-227.

46 Morgan G, Palumbo A, Dhanasiri S, Lee D, Weisel K, Facon T, Delforge M, Oriol A, Zaki M, Yu X, Sternas L, Jacques C, Akehurst R, Offner F, Dimopoulos MA: Overall survival of relapsed and refractory multiple myeloma patients after adjusting for crossover in the MM-003 trial for pomalidomide plus lowdose dexamethasone. Br J Haematol 2015; 168:820-823.

47 Rajkumar SV: Panobinostat for the treatment of multiple myeloma. Lancet Oncol 2014;15: 1178-1179.

48 Sonneveld P, Avet-Loiseau H, Lonial S, Usmani S, Siegel D, Anderson KC, Chng WJ, Moreau P, Attal M, Kyle RA, Caers J, Hillengass J, San Miguel J, van de Donk NW, Einsele H, Bladé J, Durie BG, Goldschmidt H, Mateos MV, Palumbo A, Orlowski R: Treatment of multiple myeloma with high-risk cytogenetics: a consensus of the International Myeloma Working Group. Blood 2016;127:2955-2962.

49 Malard F, Harousseau JL, Mohty M: Multiple myeloma treatment at relapse after autologous stem cell transplantation: a practical analysis (review). Cancer Treat Rev 2017;52: $41-47$. 